\title{
Development of Motivation for Achieving Professional Success of Technical Specialties Students in Russia During Practical Training at Industrial Enterprises
}

\author{
https://doi.org/10.3991/ijet.v15i16.14709 \\ Viliam Ďuriš $(\bowtie)$ \\ Constantine the Philosopher University in Nitra, Nitra, Slovakia \\ vduris@ukf.sk \\ Sergey G. Chumarov, Lidia N. Vasileva \\ Chuvash State University named after I. N. Ulyanov, Chuvash, Russia
}

\begin{abstract}
The article deals with the issues of motivation of students of technical universities to professional activity by means of industrial practices. The concept of industrial practice is considered, the goals, tasks, and functions of students' practical training in the specialty "Radio Engineering" are clarified. The peculiarities of the practice organization are noted. Based on the results of the diagnostic study, the authors conclude that the origin of students' industrial practice contributes to an increase in the level of need for success. The learning process becomes more interesting, emotionally and personally significant.
\end{abstract}

Keywords-Motivation, interest, engineering motivation, industrial practice.

\section{Introduction}

In the modern educational paradigm, the issue of practice-oriented training of bachelors becomes particularly relevant. Industrial practice is one of the forms of development of competencies necessary for successful and effective professional activity [1]. The system of practical training contributes to the intellectual development of students, the acquisition of subject knowledge and skills, the development and increase of motivation for professional activities, awareness of themselves as a competent specialist.

In this regard, it is necessary to review organization, content, forms and methods of professional training of modern students of technical universities at all its stages, the most important of which is the stage of professional formation of the student's personality. The relevance of the problem of professional training of students is due to the fact that during the period of study at university, the foundations of professionalism are laid, the need and readiness for continuous self-education or MOOC [2] is formed in changing conditions.

By professional motivation we mean a set of factors and processes that, reflected in the mind, encourage and direct the individual to study future professional activities. 
Professional motivation acts as an internal driving factor for the development of professionalism and personality.

In [3] investigated students' motivation in terms of three motivational constructs towards learning a foreign language: instrumental motivation, integrative motivation and personal motivation based on Likert scale motivational questionnaire. The article [4] compared the required skills within the "Trainee programs" that you can pass in some industrial businesses right after graduating and innovations introduced during the engineering study. This will result in a recommendation for employers and at the same time for a study program, with regard to improving the skills of the graduate in the labor market. Authors present survey [5] consists in determination of whether students are themselves motivated to acquire new knowledge, and assess whether a university education is more important compared to the skills obtained in practice. In [6] authors gives the plan of professional courses and engineering leading talent and management courses, and gives a variety of types of high-end industrial enterprises selection strategy combined with the computer professional classification. In [7] authors consider the three aspects such as characteristic of running a school, specialty characteristic extraction, University-Enterprise union cultivation pattern and, the reformation of cultivation pattern in Shenyang Ligong university for measure and control specialty. Colleagues from Ulyanovsk State Tech University consider enhance the competences of trainees (students and employees) through the development and implementation of methods, models and tools for project solutions' analysis, and through the formation of personalized training on basis of the uniform intelligent project repository [8]. The article [9] summarizes regional research, tracking the changes occurring in the technical universities of Sverdlovsk region in connection with the ongoing modernization of education. It evaluated such an important aspect of modernization, as the interaction of education and industry.

However, the problem of forming motivation of students of technical universities during their practical training has not been sufficiently developed to date.

\section{Research Methods}

During the research we used the following methods: theoretical (systematization and generalization, analysis of pedagogical and methodological literature, normative and program-methodical documentation, Internet resources; generalization; forecasting, and design); diagnostic (testing); empirical (pedagogical observation); experimental (pedagogical experiment); methods of mathematical statistics and tabular representation of results.

The experimental base of the research was The Federal State Educational Establishment of Higher Education "The Chuvash State University named after I. N. Ulyanov". The study of the problem was conducted in three stages: in the first stage was carried out theoretical analysis of existing methodological approaches in psychological and methodical literature, the thesis on the research topic highlighted the problem, idea, purpose and methods of research, a plan of experimental research; at the second stage, a system for organizing industrial practice was developed, a set of 
components of this system was identified and justified, focused on the development of motivation for achieving professional success of students of technical universities; at the third stage, experimental work was carried out, the conclusions obtained during the pedagogical experiment were analyzed, checked and clarified, the results were generalized and brought into the system.

\section{Results of the Research}

The purpose of the research is to study the motivation for achieving professional success of students of technical universities during their practical training. Industrial practice is a mandatory element of bachelor's training in the specialty 11.03.01 "Radio Engineering", profile - "Radio Engineering devices of transmission, receiving and processing of signals". The practice is provided by the Federal state educational standard 3++ [10] and the curriculum.

While studying at the university, students who study under the professional standard 06.005 - "Electronics Engineer" pass three types of industrial practice: project practice, technological (design and technological) practice and research work. Students develop various competencies necessary for their future professional activities.

Industrial practice (practice for acquiring vocational skills and professional experience) aims to deepen and consolidate the theoretical knowledge, abilities and skills obtained by students earlier in the study the subjects of the curriculum; studying the enterprise organizational structure at the place of practice and current control systems; familiarization with the contents of the main works and studies performed by the organization at the place of practice, participation in research; mastering techniques, methods and methods for detecting, observing, measuring and controlling the parameters of the studied processes; mastering techniques, methods and methods for processing, presenting and interpreting the results of research.

The objectives of the practice are to consolidate, expand and deepen knowledge, skills and abilities in the following areas: consolidation in practice of knowledge, skills and abilities obtained in the course of theoretical training; the development of professional skills and business communication skills; acquisition of practical skills of independent work in the workplace; development of search activity in the solution of production problems; collecting the necessary materials for writing reports on practices.

The result of practical activity of bachelors is directly related to the functions of practice and is expressed in professional competencies: 1. Functions of the production practice; 2 . Training: updating, deepening and expanding theoretical knowledge, their application to the solution of specific situational problems, the formation of skills and abilities; 3. Developing: development of cognitive and creative activity of future specialists, development of thinking, communication and psychological abilities; 4. Educational: bachelor's awareness of their own professionally significant and personal qualities, the need for engineering and readiness to perform it responsibly; 5. Organizational: students master the rules of organizing the teacher's activities, they form skills related to the organization of individual, group, and collective forms of work; 6 . 
Diagnostic: checking the level of professional orientation of future specialists, the degree of professional fitness and readiness for professional activity; 7. Analytical: analysis of students' own directed professional activity in order to determine the level of knowledge acquired at the university, formed on the basis of their skills as an indicator of readiness for independent work as an engineer

During the period of practical training, students must fully implement the theoretical training received during their years of study at the University. Students perform a certain amount of research and experimental work, which completes the initial stage of becoming a student as an engineer. During the period of industrial practice, the student's intensive self-determination as a specialist takes place.

In the process of synthesis of the accumulated experience of experiencing the social and personal significance of moral norms, actualization of morally valuable needs, a unique individual meaning of their own existence as a professional is born, which further motivates the behavior and activities of students.

The process of becoming a student as a future engineer has a significant impact on the formation of the motivational sphere, since "motivation organizes a holistic behavior, increases the activity of the individual, affects the formation of goals and the choice of ways to achieve it, has a significant impact on the results of educational activities" [11].

For the organization of the learning process, it is important to consider the possibility and productivity of forming motivation through changing the goal setting of educational activities.

Researchers distinguish two groups of motives: cognitive, related to the content of educational activities and the process of its implementation, and social, related to various social interactions of the student. Cognitive motives include: broad cognitive motives (focus on mastering new knowledge); educational and cognitive motives (orientation on learning ways of obtaining knowledge); motives for self-education (focus on self-improvement of methods of obtaining knowledge).

Social motives include: broad social motives (the desire to acquire knowledge based on awareness of social necessity); narrow social (the desire to take a certain position, place in relationships with others, to get approval from parents, teachers, friends); motives of social cooperation (communication and interaction with other people, awareness of the forms, ways of cooperation and relationships with teachers, parents, friends and their improvement) [12].

Let's consider the experience of organizing industrial practice at the Chuvash state University, on the example of training students in the specialty 11.03.01 "Radio Engineering". The practice is conducted in organizations of various industries, spheres and forms of ownership, in academic and departmental research organizations, state and municipal authorities, whose activities correspond to the direction of training (profile organizations) under the guidance of practice managers.

Production of electronic equipment is a set of interrelated processes by which a person creates necessary products from raw materials and electronic products intended for use in the sphere of consumption or production. The development of modern production is characterized by a continuous process of updating the material and tech- 
nical base and production technology, the complexity of the production preparation cycle, and complex mechanization and automation of production processes.

Here is an example of a project for the production of a prototype, in which students participate together with engineers of industrial enterprises of the Chuvash Republic. Large projects can be divided into several design stages. Each stage can be performed by the student independently under the supervision of an engineer or together with him. The communication unit on the ks8995ma chip is designed to provide communication over the Ethernet interface with external equipment of industrial control systems. The KS8995MA chip is designed for building network switches using the IEEE 802.3/Ethernet 10/100 Mbit/s Protocol up to five ports.

This project is carried out on the basis of studying the features of operation and characteristics of switching equipment during training at the Chuvash State University in the following disciplines: Information processes in radio electronics, Design of microcontroller electronic devices, etc. There are two ways to access and manage the switch: over an IP network using the web interface, or through the console port using the switch's command-line interface.

Importance is attached to learning computer modeling and design, as well as using application packages such as Mentor Graphics [13]. Design and simulation technologies of Mentor Graphics has long been popular among Russian specialists, as it provides modern integrated technologies for designing and modeling electronic systems and equipment. One of the most popular Mentor graphics products is the Xpedition platform. In various modifications (for example, PADS Professional), this PCB design platform is necessary when designing complex and high-speed electronics.

Figure 1 (a) shows the two-layer printed circuit board of the communication unit routed in Mentor Graphics (the Bottom layer is disabled), and figure 1 (b) shows its 3D model on SMD components. From the figure it is seen that the differential pairs of the block PCB are correctly routed thanks to the HyperLynx project validation and verification option. The two-layer printed circuit Board is made using surface mounting technology.

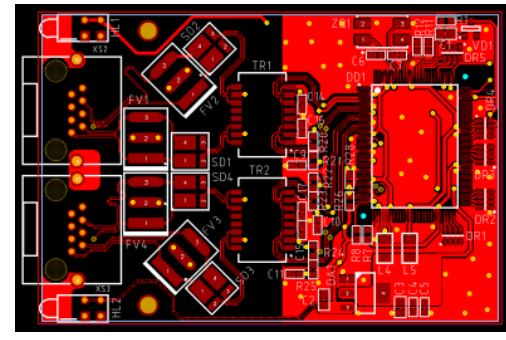

(a)

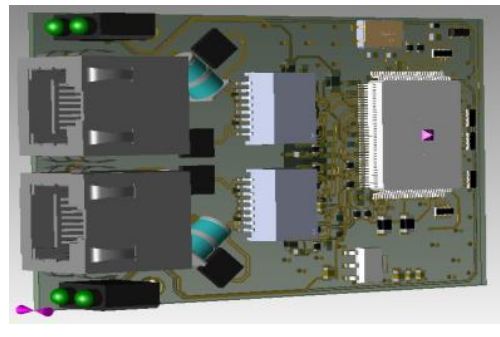

(b)

Fig. 1. Communication unit printed circuit board

Designing the electronic equipment as one of the types of engineering activities, is the process of defining, designing and reflection in design, technological and programme documentation: the shape, dimensions and composition of the products; con- 
stituent parts and components; materials and components products; mutual arrangement of parts and connections between them; guidance on fabrication technology, instructions for metrology verification and methods of using the products.

An external enclosure is provided for the communication unit (Figure 2). KOMPAS-3D was used for its design and design documentation [14]. KOMPAS-3D allows you to improve the quality and speed of design of electronic equipment.

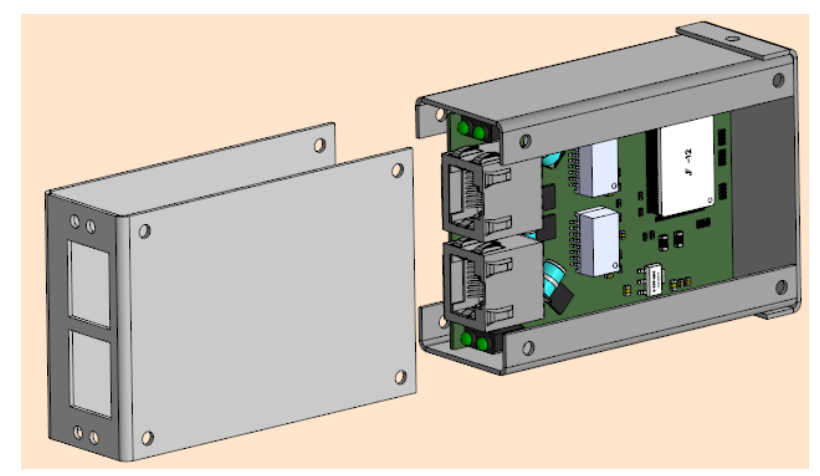

Fig. 2. Communication unit in external enclosure

Next, students study the process of manufacturing body parts at machining centers with computer numerical control (CNC) using modern tooling. CNC is one of the means of automation of small-scale and serial production. Programming is performed in a language known as ISO 7 bit, also referred to as the $\mathrm{G}$ and $\mathrm{M}$ code language using CAM systems [15].

The study of the level of development and achievement of professional success in students of technical training areas was conducted on the basis of the analysis of experimental work experience under natural conditions of the educational process and the comparative homogeneity of the composition of students. The study covered 47 fourth-year students of the faculty of radio Electronics and Automation. Evaluation of the effectiveness of the impact of practical training on the motivation to achieve professional success was performed using the method of Orlov Yu. M. "Testquestionnaire. The need to achieve the goal. Scale of assessment of the need to achieve success" [16, 17].

All the questions you need to answer "Yes" or "No". The key to the Orlov testquestionnaire is as follows: answers "Yes" to questions: 2, 6, 7, 8, 14, 16, 18, 19, 21, 22; answers "No" to questions: 1, 3, 4, 5, 9, 11, 12, 13, 15, 17, 20.

For each answer that matches the key, 1 point is awarded. The sum of points is calculated. Orlov's method is interpreted as follows:

1. $0-6$ points correspond to low motivation in achieving the goal

2. $7-9$ points correspond to reduced motivation in achieving the goal

3. $10-15$ points correspond to the average motivation to achieve the goal

4. $16-18$ points correspond to increased motivation in achieving the goal

5. $19-22$ points correspond to high motivation in achieving the goal 
Table 1 presents the results of the distribution of students by levels of need for success before and after the use of blended learning.

Table 1. Levels of formation of indicators of students' need to achieve success

\begin{tabular}{|l|c|c|}
\hline \multirow{2}{*}{ Indicators of the need for success } & \multicolumn{2}{|c|}{ The experimental group } \\
\cline { 2 - 3 } & $\begin{array}{c}\text { At the beginning of the exper- } \\
\text { iment }\end{array}$ & $\begin{array}{c}\text { At the end of the } \\
\text { experiment }\end{array}$ \\
\hline $0-6$ points - low need for achievements & 2 & 0 \\
\hline $7-9$ points - reduced need for achievement & 3 & 2 \\
\hline $10-15$ points - the average need for achievement & 40 & 37 \\
\hline $16-18$ points - increased need for achievement & 2 & 8 \\
\hline $19-23$ points - high need for achievement & 0 & 0 \\
\hline
\end{tabular}

Table 1 shows that the number of students who had high indicators of need for success at the end of the experiment significantly increased due to a decrease in the number of students who had low indicators of need for success at the beginning of the experiment.

A statistical analysis of the assessment of the need to achieve success in order to check the effectiveness of practical training was conducted. The Wilcoxon $T$-test was used for statistical processing of the presented results. According to the table, the critical value of $T_{C R}=407(n=407)$ at the significance level $\alpha=0.05$.

In the process of processing the results, the following hypotheses were put forward: $\mathrm{H}_{0}$ : indicators of the level of assessment of the need for success at the end of the experiment are higher than the values of the indicators before the experiment. $\mathrm{H}_{1}$ : indicators of the level of assessment of the need for success at the end of the experiment are higher than the values of the indicators before the experiment.

The empirical value of $T_{E M P}=44+14.5+35+44+14.5=152$ according to the results of diagnostics at the beginning and end of the experiment falls into the zone of significance: $T_{C R}>T_{E M P}(407>152)$. The hypothesis H0 is accepted. Indicators of the level of assessment of the need for success after the experiment exceed the values of indicators before the experiment. In the statistical analysis using the Wilcoxon T-test of indicators of the level of assessment of the need to achieve success before and after the experiment using the method of Orlov Yu. M. "Testquestionnaire. The need to achieve the goal. The rating scale needs to achieve success" gives the following result: the Level of assessment of the need for the success of the students after the internship is statistically significantly higher level of development assessment of the need for the success of the students before the internship.

\section{Conclusion}

The study confirmed the hypothesis that the passage of industrial practice by students contributes to an increase in the level of need for success. The learning process becomes more interesting, emotionally and personally significant.

The authors are convinced that practical training contributes to a more concerned attitude of students to the educational process actualizes the needs of students in self- 
expression, and inspires them to find new, professionally significant information, which later transform in General and vocational information, relevant to specialization of expertise.

\section{$5 \quad$ References}

[1] Chuchalin A., Minin M., Vyuzhanina, N. (2014). Practice-oriented Learning as a Way to Meet Employers' Requirements to Graduates. In: International Journal of Engineering Pedagogy (iJEP), Vol. 4, No. 2., pp. 31-35, eISSN: 2192-4880, https://doi.org/10.3991/ijep. $\underline{\mathrm{v} 4 \mathrm{i} 2.3440}$

[2] Xi J., Chen Y., Wang G. (2018). Design of a Personalized Massive Open Online Course Platform. In: International Journal of Emerging Technologies in Learning (iJET), Vol. 13, No. 4., pp. 58-70, eISSN: 1863-0383, https://doi.org/10.3991/ijet.v13i04.8470.

[3] Bobkina J., Caleya M. (2012). Motivation and Attitudes towards Learning English: a Study of Engineering Undergraduates at the Technical University of Madrid. In: 5th international conference of education, research and innovation (ICERI), 2012, p. 4492-4501.

[4] Kuperová M., Zatrochová M. (2019). Innovations of Study Programs in Comparison with Requirements of Industrial Enterprises' Trainee Programs. In: $33^{\text {rd }}$ International-BusinessInformation-Management-Association Conference, April, 10. - 11., 2019, Granada, Spain, p. 2014-2023.

[5] Špakovská K., Miklošíková M., Vanek M, Ballarin M. (2014): Factors affecting the motivation and success of technical university students. In: 14th International Multidisciplinary Scientific GeoConference (SGEM 2014), Conference Proceedings, p. 597-604, DOI: https://doi.org/10.5593/SGEM2014/B53/S22.079

[6] Gu S., Zhang C., Jiang J., Chu D., Li J., Lv W. (2018). Curriculum Construction and Enterprise Selection for Engineering Leading Talent Training in Computer Specialty. In: $2^{\text {nd }}$ International Conference on Education, Economics and Management Research (ICEEMR 2018), Vol. 182, p. 13-18, https://doi.org/10.2991/iceemr-18.2018.4.

[7] Gao H., Yu Y., Chen L. (2015). New engineering talents cultivation mechanism based on cooperation for government, industrial cluster and college. In: $3^{\text {rd }}$ International Conference on Education Reform and Management Innovation (ERMI 2015), Vol. 79, p. 9-14.

[8] Alexander A., Voit N., Ionova I., Ukhanova M., Yepifanov V. (2018): Development of the Intelligent System of Engineering Education for Corporate Use in the University and Enterprises. In: $20^{\text {th }}$ International Conference on Interactive Collaborative Learning (ICL 2018), Vol. 715, p. 716-727. https://doi.org/10.1007/978-3-319-73210-7_84

[9] Boronina L., Bannikova L., Baliasov A. (2016). Organizational forms of interaction of university with industrial partners in the new format of engineering education. In: $8^{\text {th }}$ International Conference on Education and New Learning Technologies (EDULEARN 2016), p. 3627-3632. DOI: 10.21125/edulearn.2016.1829.

[10] Order of the Ministry of Education and Science of Russia 06.03.2015 № 179 "About the approval of the Federal state educational standard of higher education in the field of training 11.03.01 radio engineering (bachelor's level)", registered by the Ministry of Justice of Russia 20.03.2015 № 36509 .

[11] Shadrikov, V. D. (1994). Activities and abilities. Moscow: Logos, 320 p.

[12] Gamezo, M. V., Petrova E. A., Orlova L. M. (2003). Age and educational psychology: a textbook for students of all specialties of pedagogical universities. Moscow: Pedagogicheskoe obshchestvo Rossii, 512 p.

[13] Mentor, a Siemens Business URL: mentor.com (access date: 23.03.2020). 
[14] Kompas-3D URL: kompas.ru (access date: 23.03.2020).

[15] Li X., Ding S., Wei J., Wang Q. (2017). Research on Teaching Method of Mold Course Based on CAD/CAE/CAM Technology. In: International Journal of Emerging Technologies in Learning (iJET), Vol. 12, No. 7., pp. 136-145, eISSN: 1863-0383, https://doi.org/10.39 91/ijet.v12i07.7224.

[16] Eliseev O. P. (2003). Praktikum po psihologii lichnosti. SPb., 272 p.

[17] Golova L. A., Rybalko E. F. (2001). The age psychology practicum. SPb., pp. 497-498.

\section{Authors}

Viliam Ďuriš studied mathematics and computer science and has been an assistant professor at the Department of Mathematics of the Faculty of Natural Sciences of Constantine the Philosopher University in Nitra, Slovakia, since 2009, focusing mainly on object programming, applied mathematics and numerical mathematics. He is an author of many major projects and training systems and has also been involved in major national and international projects. As expert in information technology and professional database programmer runs his IT projects worldwide. Contact: Department of Mathematics, Constantine The Philosopher University in Nitra, Tr. A. Hlinku 1, 94974 Nitra, Slovakia, email: vduris@ukf.sk.

Sergey G. Chumarov received the engineering degree in radio engineering from Mari State Technical University, Yoshkar-Ola, Russia, in 1999 and the PhD. degree in radio engineering from Mari State Technical University, Yoshkar-Ola, Russia, in 2002. Since 1999, he has been with the Department of Radio Engineering and Telecommunications, Chuvash State University, where he is currently an Associate Professor of the Department. His current research interests include radio signal processing, adaptive filtering and wavelet transform. Contact: Department of Radio Engineering, Chuvash State University, 428015 Cheboksary, Russia, email: chumarov@mail.ru.

Lidia N. Vasileva received the higher education in mathematics from Chuvash State University, Cheboksary, Russia, in 2000 and the PhD. degree in pedagogics from Chuvash State University, Cheboksary, Russia, in 2015. Since 2017, she has been at the Department of Automation and Management in Engineering Systems, Chuvash State University, where she is currently an Associate Professor of the Department. Her current research interests include engineering education, teaching methods of computer science and mathematics. Contact: Department of Automation and Management in Engineering Systems, Chuvash State University, 428015 Cheboksary, Russia, email: oln2404@mail.ru.

Article submitted 2020-04-08. Resubmitted 2020-06-01. Final acceptance 2020-06-03. Final version published as submitted by the authors. 